\title{
Gender and its Stories
}

\author{
Paolo Rigliano, * Federico Ferrari, ** Enrico Maria Ragaglia***
}

\begin{abstract}
The following work deals with several issues concerning gender. Firstly, it examines several anthropologic and historical dynamics concerning the establishment and legitimacy of male power, in opposition to the subordination of everything that concerns the female domain and the existence of women. In detail, it focuses on learning processes and the enhancement of the bipartition of gender in the family, in school and in different means of communication. The birth of gender studies will be described as an original field of study in various areas of human knowledge and how this has allowed for the diffusion of social and cultural awareness based on objective data. Lastly, we will consider the reasons that have led to the birth of gender theories on behalf of fundamentalist American and European groups, who then launched an international campaign: the religious and ideological suppositions, methods, strategies and aims of these campaigns against the presumed dominion of gender theory will be described. Future developments of these movements will be outlined, together with their strategies.
\end{abstract}

Keywords: Gender, gender socialization, sexual identity, gender studies, gender theory, fundamentalism.

\section{Gender anthropology}

The study of present and past cultures shows us how the norms on femininity and masculinity are variable in both time and location: the customs related to being man and woman in our society are intensely different from those in Islamic countries, Scandinavian countries or Asian countries, and in these different places customs have changed dramatically over the centuries.

\footnotetext{
*Psychiatrist, Psychotherapist. Head of the Centro Giovani "Ponti" della ASST "Santi Paolo e Carlo" in Milano. E-mail: Rigpaolo@libero.it

**Psychologist, Psychotherapist, Professor of Systemic Relational Therapy and of the Open Dialogue Approach. E-mail: federico_ferrari@yahoo.it

***Psychologist, expert in sexual identity and processes of social inclusion and participation. He is involved in both clinical, diagnostic and educational activities.

E-mail: psicologo@enricomariaragaglia.it
} 
Nevertheless, it is evident that in many cultures, including the Italian one, the feminine role has been historically, and still is, subordinated to the male one. According to anthropologists, however, prehistoric nomadic hunter gatherer societies in the Mesolithic and Neolithic periods presented an egalitarian and non-hierarchical gender role division. This is still the case in populations that preserve this method of acquiring sustenance (Endicott, 1999).

However, in these societies, there was already a privileged distribution of roles that saw women as mainly gatherers and men as hunters. Beginning from this division of labour around 12,000 years ago, with the advent of social organizations that were based on sedentism and agriculture, the formation of hierarchical structures with male dominance accompanied an androcentric distribution of power (Alesina, Giuliano, \& Nunn, 2011). In other words, due to various factors, power and hierarchies have been created and perpetuated putting the male and masculinity at the centre. The fact that things have turned out like this does not mean that they must go on in the same way, or that, in theory, they could not have gone in another way, if only certain factors had been different. When a similar discussion is held between researchers who study human evolution, this invites us to be modest on behalf of the human species for several different reasons. What happened, is that the species Homo sapiens sapiens became dominant compared to other Homo genera, but it could also have not turned out this way. Some academics attribute this primitive division of gender roles to an adaptation to individual reproductive roles: since women were considered to be in a more fragile condition during pregnancy, they were given non-violent and more sedentary roles, which involved caring and the provision of food and water. While men were assigned to defend the territory, hunt and go to war (Bird, 1999). This hypothesis is useful for understanding the vast diffusion of a norm, which does however have exceptions. Although there is no convincing proof of the existence of a truly matriarchal society, in which the political power was a female prerogative (except for a few unverified sources about this being present in Brazil and Libya in a historical epoch), there has been evidence of egalitarian civilisations regarding the sharing of power, and also cultures in which the practice of war was common in women (Anthony, 2007; Edgerton, 2000). There are also legendary queens that have engraved their names in the history of ancient eastern civilizations (Semiramis foundress of Babylon, Artemisia of Halicarnassus and Cleopatra VII of Egypt) that testify to a participation by women to the highest political powers.

\section{Gender and its vicissitudes}

Even though in every era there has been a variety between different places, in the history of the west, the female condition has encountered important evolutions only in the last few centuries. 
In the ancient world, in Greece (with the exception perhaps of Mycenae) women had to choose between being property of their husbands or being courtesans. Even in Rome, albeit acquiring some rights based on social class, women still remained noticeably subordinated to their husbands. They did not have political rights, nor authority over their children. This subordination remained steadfast also in Judaic tradition, which established in the stories of Creation and of Sin from the Old Testament a conception of women being submissive to their husbands and dedicating their time entirely to maternity and procreation. This idea was maintained, or was only partially surpassed, with the message of the New Testament: after the strong innovative impacts of the early Christian communities preaching, the later conservative interventions of Saint Paul had the effect of firmly containing these changes. In general, Christianity seemed to bring with it a new cultural centrality of the female role, however, her importance was bound to being complementary to her father and husband, to whom the woman was completely submissive. Furthermore, women's political power was completely barred.

During Medieval times, the female condition saw a slight improvement: sometimes women were allowed to: inherit noble riches and titles, access craft professions and corporations.

With the Renaissance, women among higher social classes had more access to public life, even though their autonomy diminished (King, 1991). Working life and political influence were practicable by women by virtue of the social status offered to them by marriage (and by their parents), who, in exchange, imposed obedience and subordination. Alternative choices were those of renouncing one's respectability in lieu of relative freedom, becoming a courtesan, or embracing monastic life. From the 14th century, the Holy Inquisition took on, not only the persecution of heretics, but also the task of hunting witches. For three centuries the Catholic Ecclesiastical Tribunals, the Protestant Reformation and many civil authorities took to trial at least 110,000 people and burnt at least 60,000 at the stake, $80 \%$ of which were women (Henningsen, 1990). The phenomenon of female disobedience was intertwined therefore with the access of women to forms of power reserved to them by pagan traditions (such as medicinal rituals), thus making them subject to unprecedented demonization and persecution. In the 17th century, in the face of the Catholic Counter Reformation, a generalized sexual phobia prevailed, in which the only acceptable female conditions were those of wife and nun. In this way, bourgeois women obtained more education, albeit limited, regarding the domains that were considered pertaining to them. In the case of the upper and aristocratic classes, the literary salons organized by women became occasions for intense cultural exchange, though women remained excluded from the scientific community and from universities. 
In the $18^{\text {th }}$ century, the age of Enlightenment and the French Revolution contributed to the formation of the principles of equality between male and female citizens (Wollstonecraft, 1792; De Gouges, 1793), but with the conclusion of the revolutionary aspect, such instances were not fully accepted. Despite women maintaining more of a presence in the cultural world, the prejudice of women being naturally inferior to men still prevailed, and this was used as a way of not extending their political rights.

As such, for all of the $19^{\text {th }}$ century, the female situation did not change on a political front, although it did begin to become a subject of reflection (Belgiojoso, 1848). However, the Industrial Revolution led working-class women to leave the house more and go out to work in factories. Moreover, education became more accessible to larger swathes of the population, including women. However, their separate curriculum was aimed at training them to be wives housekeepers. In parallel, we witness to a transformation of the typical family model, with the consequential reduction in the average number of children, despite the notable differences between cities and the countryside. In the north of Europe, the debate regarding civil equality of men and women was becoming progressively more heated, so much so that by 1866 Sweden was the first country to guarantee voting rights for women, followed by New Zealand in 1893. In 1869 the so called suffragettes were born in England, a social and political movement that carried out forms of civil protest, hunger strikes and public rallies to lay claim to the female right to vote. They obtained this in 1918, initially only for wives who were 30 years old or more, then in 1928 the right was extended to all adult women. In 1919 it was Germany's turn, in 1920 the United States, while in Italy and France women had to wait until 1945.

Therefore, in the first twenty years of the $20^{\text {th }}$ century, along with the Suffragettes, what was known as the first wave of feminism was born. Feminist thinking grew stronger with the two world wars, due to the need for women to work as well as men. Shortly after the First World War the first feminist writings of Virginia Woolf and Rebecca West emerged, while those of Simone de Beauvoir appeared after the Second World War. Starting from the last-mentioned female author and during all of the $50 \mathrm{~s}$ and $60 \mathrm{~s}$, the movement evolved both by identity and organization to what we now call the second wave of feminism. The mindset of the second wave reached peak maturity with the sexual revolution of 1968 , concentrating on the problem of discrimination towards women. The link between female discrimination and a system of representation of reality, of thought and of culture was denounced as not only male but also decidedly phallocentric and sexist. This sexist system was based on the principle of male normativity that considers the female gender as inferior, weaker, unable to decide for themselves, and that therefore needed constant male supervision.

The battles of this second wave of feminism consisted firstly in the right 
to have female self-determination, which is expressed by: i) the ability to decide who to have relationships with; ii) the capacity to divorce without fault (up until then, it was in fact, a husband's prerogative to repudiate his wife, while she was allowed only to be repudiated); iii) the ability to decide about bodily integrity, rejecting sexual intercourse with one's husband (one must only think of the introduction of the laws regarding marital rape); iv) the right to contraception and abortion.

In the 80 s thoughts developed progressively more strongly towards a claim of equal opportunity, that is, of female representation in cultural and scientific work, and of access to contexts of power traditionally reserved for men. These requests were put forward on the basis of difference feminism, the ideology that laid claim to rights starting from the re-evaluation of a difference that was considered natural, but culturally played down and marginalized by male power.

In the $90 \mathrm{~s}$, in view of a substantial continuity in the vindication of women's rights, feminist thinking accomplished a step forward thanks to Afro-American and postcolonial feminism, that highlighted how female subjectivity was varied and tied to racial, ethnic and cultural contexts. It was from this vision of plurality and diversity within diversity that the idea took off; gender was considered the result of daily acts. Starting from the preconception of differences between men and women, a concrete reality was produced that confirmed gender categories (this reference is to the philosophical deconstructionist concept of Althusser, Foucault and Derrida) (Butler, 1990). One therefore understands why in this vision, the subjectivities that are considered eccentric and subversive are those that challenge power structures that force individuals into frameworks, representations and binding realities.

We have traced this brief historical journey regarding the evolution of this issue regarding women. However, we could have undertaken another historical and cultural path, dealing with homosexuality and transsexualism. What is missing you may ask? The important absentee is the discussion on the male gender and on heterosexuality as a sexual orientation. This is not by chance. In being the centre of everything, the heterosexual male as a denominator, has circumvented the problem of self-definition. He has never had to define himself because it is taken for granted. The historical, social and academic context has never educated him to do so and has also never given him the tools necessary to understand himself and tell his story. The heterosexual male has had to define and identify himself mostly via differences between him and his complement, i.e., the female heterosexual, who is often underrated and subjugated: don't be weak, don't be a gossip, don't be a pansy.

This is no longer the case and men now have to face a deconstruction of these male and female models and their reciprocal contamination. This is 
also thanks to an encountering of homosexuality that vindicates its own human worth, refuting the role of queer (non-male or non-female).

\section{Gender socialization: in families}

The fact that an individual is female or male from birth produces an effect on the people who care for that individual, influencing their way of relating to him/her. Research shows that straight away parents tend to have different expectations regarding male children or female children, and these are acted upon at all different levels (Lloyd \& Duveen, 1990; Beal, 1994).

Especially in the first few years expectations influence perceptions that parents have of their children and their traits or characteristics: for example, fathers generally consider males as stronger and females as more fragile. Although the effect of this was attenuated in the second half of the last century, it is still significant (Karraker, Vogel, \& Lake, 1995). In daughters, it is possible that calm behaviour is interpreted as a trait of tenderness, but it may go unnoticed in a male child; similarly, a particular game could be a sign of strength in a son, while it may remain irrelevant in a daughter, and so on.

Furthermore, already from six to fourteen months, studies demonstrate that from these diverse expectations, different parenting styles emerge, that tend to involve the parents in a different manner in different activities. Parents have more conversations with their daughters (to interpret their behaviour) and they generally give more instructions to male children (Clearfield \& Nelson, 2006). Emotions are discussed more with daughters than with sons, and the reactions of the parents to each other's negative emotions are different, reinforcing the emotions of sadness and fear in daughters, who pay more attention to these, and those of anger and pride in their sons (Fivush, Brotman, Buckner, \& Goodman, 2000; Chaplin, Cole, \& Zahn-Waxler, 2005; Garside \& Klimes-Dougan, 2002). Similarly, a contradictory sentimentality to a child's gender (aggressiveness in a girl or fear in a boy) can be perceived as irritating and wrong, and so will be discouraged rather than indulged.

Daughters and sons can internalize the expectations of their parents with regard to their predispositions/attitudes to one type of activity rather than another. This will have an effect on motivation and on the attitude with which they will face different types of tasks. These will in turn influence, to a varying degree, learning processes and academic results, thus confirming their initial expectations. For instance, if a child expects to be good at mathematics, he/she will confront it with more optimism, motivation, practicing more, optimizing learning processes and confirming the expectations of a predisposition. If he/she confronts the same task with the idea of being successful only at the cost of a lot of hard work and dedication, he/she will 
probably be less motivated and will obtain poorer results, or he/she will have more anxiety during the task, confirming the expectations of his/her non-predisposition. Research suggests that in male children the tendency is to attribute their success in mathematics and sport to personal talent, while in the case of female children the tendency is to ascribe the same successes to individual efforts. Vice versa this also applies to language or verbal talents (Eccles, Jacobs, \& Harold, 1990; Brustad, 1996) for which female success is attributed to talent and male success is associated with hard work.

Lastly, in conversations and in household practices the gender roles are referred to and acted out by parents. Mothers and fathers often dedicate their time to different household practices, and even if we are progressively moving towards the idea that division of labour should be equal, we are still far from a real generalization in daily practice. Furthermore, mothers and fathers show different relationship modalities, they talk about different issues and express their gender roles in their judgments and their relationships with other people. All of this constitutes a culture of family gender, a soup of emotions, affections and representations that children can internalize as references.

\section{Gender socialization: at school}

While within families there is this differentiation from the start, gender socialization at school comes about only after the first few years of life. Teachers, therefore, have to contend with a population of children that can statistically already present some differences to relationship and attitudinal predispositions, but which, in reality, are still very malleable. The school environment represents a context in which differences between boys and girls are structured and amplified. Research has shown that there are at least 3 factors that tend to reinforce gender socialization as though it were a lesson issued by the school, without an explicit intent (the so-called hidden curriculum), but which can be seen clearly. These factors are:

i) Teachers and school staff: in a similar way to parents, teachers can have preconceived ideas on the difference between males and females, that condition the answers that they give students of one sex or the other. For instance, they can reprimand a girl more sternly when they behave aggressively and yell at a boy who often asks for reassurances. In addition, they can offer explanations of educational success and failure, which confirms the idea that there is a gender predisposition towards certain activities, rather than others, demonstrating varying levels of trust in their students regarding different tasks. Moreover, teachers can encourage separate activities between males and females and can behave differently with males and females during recess, favouring a different 
level of dialogue with one or the other. Even a gender-neutral attitude on behalf of the teacher, indulges, factually and uncritically, differentiation processes that are fostered at home, between peers and in the mass media. There are few cases in which the teacher strives to counterbalance the conditioning that is instituted by extra-scholastic settings.

ii) Educational support and teaching materials: schoolbooks, films, narrated stories and class posters are all tools that transmit a specific representation of reality in which children can identify themselves in and from which they deduce naïve theories about reality. Research shows that the majority of educational support materials, still to this day, transmit stereotypical images of gender roles. For example, family representations tend to show dads on a sofa with a newspaper and mums in the kitchen with an apron on. Stories describe males as bold, fierce, and strong and females as vain, emotional, and fragile; males are depicted outside in the open air, and females indoors. Hence, they depict characters carrying out certain activities that are considered appropriate to their gender, according to common stereotypes (Serravalle Porzio, 2001).

iii) Other cornerstones of the school environment are the relationships with one's peers: Ever since nursery school, our peers offer us a sense of belonging and the possibility to identify with them, starting with rules that are more or less implicit and shared. From three years onwards gender seems like an important category in order to define these group rules. Few other categories, in fact, are so accessible so early on for children, because the gender rule presents as extremely simple (male or female), it is extremely diffuse in every representation of reality and there is a high degree of consensus in the adult world regarding it. Not much is needed for gender to become an important regulator of the relationship with one's peers, from which one is encouraged to reciprocally do male activities or female ones. When this does not occur, children tease each other, they compete to collect precious examples of superheroes who are a symbol of masculinity and of fairies and flowers which signify femininity.

Gender rules and divisions are present throughout the most significant developmental and educational years. In primary school we can witness a clear division of gender (known also by a stronger and more indicative term, that is, segregation), that continues throughout middle school and is then finally integrated and substituted by heterosexual behaviour in secondary school, both internally and externally to the group. Even scientific research has documented how the rules of popularity between peers are very distinct between males and females and represent a system that can motivate individuals to adhere to gender stereotypes and to find confirmation and positive relations with their peers (Adler, Kless, \& Adler, 1992; Weerman, 2012; Leaper \& Friedman, 2007). 
Gender socialization: in the media

The last element that we will consider and discuss is how we all become unconsciously gender socialized in the mass media. For a long time, the media have represented an imposing cultural reservoir, which can generate representations of widespread and shared realities. Newspapers, magazines, cinema, tv programs for children, the Internet, video games and advertisements are means and information tools in which individuals are immersed from a very young age. Studies have examined the types of gender models transmitted by the media and they agree on the fact that more or less in all media contexts there is an extremely standardized representation of gender.

To supplement what has already been said regarding the role of the peer group, we can add that the media have a direct effect on the definition of the rules of popularity between peers, amplifying gender socialization mechanisms acted out by one's peers (Dill \& Thill, 2007; Durham, 1999; Hardin, \& Greer, 2009; Holtzman \& Sharpe, 2015). If like in the past the push towards gender models was particularly normative and constrictive, expressing itself in rules that had to be obeyed, today on the other hand, with the liberation of morals, the push towards gender models is given by mechanisms of social desirability, promises of happiness and success that push children and adolescents to adhere spontaneously (but not freely) to the proposed stereotypes. In conclusion, family, school, and the mass media can be considered parts of a complex and interdependent system of socialization, in which the effect of one supports and amplifies the others. This creates an invisible network of references that allow us to deceive ourselves that there is a natural gender difference from the start, while in reality this is being constantly constructed and consolidated by the context for the whole of our lives. It is evident just how much this is significant during development, that is, when a person is asked to construct, define and orient their identities, including their sentimental and sexual ones.

From the birth of gender studies...

For some time now gender is one of the fundamental issues of social and scientific debate around the world. This is due to the fact that

\footnotetext{
"Gender does not entail just simple relationships between two individual bodies, but a vast and complex cultural and institutional order. It is this order, in its complexity, that relates with the bodies and gives them gender significance" (Connell, 2009),
}

and therefore, it needs multiple points of view, approaches, methods of analysis, individual and collective elaboration. So much so that 


\begin{abstract}
"Gender is a specific form of social incorporation. Gender relations form a particular social structure, they refer to particular bodily characteristics and gender practices form a circuit between these elements" (Connell, 2009, p. 128)
\end{abstract}

It is therefore necessary to unite multiple views and levels with different analysis strategies; it is necessary to foster dialogue between scientific paradigms and diverse cultural ties, that complicate the points of view and, thus, the systems in which the gender structures and orders take and give life. It is for this reason that various studies and research projects (Ferrari, 2016; Saraceno, 1996) have been conducted in various fields in academic contexts concerning these different levels, aspects, and themes of sexual identity, their origins and relations between subjects and social and cultural contexts. If we put these together, we get the name gender studies. This research started in the United States between the 60s and 80s and started to spread to Europe and then the rest of the world during the 80s. Gender studies can be situated in a much more vast category known as cultural studies, which has also contributed, for example, to the defining of contemporary approaches for studying disabling conditions. Initially, these studies were carried out by feminist movements or homosexual people, and also linguistic and ethnic minorities. Just like in all evolutions of new outlooks, there were multiple versions and interpretations, some moderate, others more radical - intertwining themselves with political, cultural and sentimental grounds tied to respective minority conditions. Just as in all scientific models, it is opportune to consider and recognize the primary and essential nucleus of theories, distinguishing it from particular articulations. We must not forget that gender studies are what allowed us to discover that sexual identity is composed of multiple levels and dimensions, that can be connected in various ways and forms. For this reason, at present, gender studies represent an important approach which is recognized by the entire scientific community (Italian Association of Psychology, 2015). These studies embrace all scientific and social disciplines in a cross-sectional manner, articulated in varying degrees and research fields that are extremely different. They represent a multidisciplinary approach to studying social, economic, psychological and cultural meanings within the different levels of sexual identity. Firstly, they constitute a way of interpreting reality, that can be applied to any context and allow us to analyse the role of factors which intervene in the construction of masculinity and femininity. It acts as a sort of lens through which we can observe sexual identity and relationships between the sexes and genders: there are those who do it through a psychological lens and those with a biological one, but all consistently focus on gender. It is interesting to note that many of these lenses have been interwoven, to present new horizons of thought and research, such as the case of psychology in gender differences. Lastly, gender studies have brought psychologists, psychiatrists, psychotherapists and psychoanalysts to rethink the 
sexual dimensions of male and female, without lessening the role of anatomy, but rather redefining it as one of the levels to take into consideration.

The fact that we can reflect on dominant gender roles and on the power relationships that stem from them and change them does not mean that we can condition sexual orientation, nor does it involve distress during the formation of sexual and gender identity for the child or adolescent. There is no scientific evidence that a child who is educated within a flexible and cultural model, that is respectful of the different ways of living masculinity-femininity, will grow up to have specific psychological disorders.

\section{...to the invention of gender theory}

Despite the real objectives of gender studies, several fundamentalist groups have instigated a campaign against a supposed gender theory. It is very important to try to understand the aims and methods of this theory. It represents an invention of the last decade that has the clear reactionary aim of presenting emancipation on the one hand of women, and on the other hand of gay, lesbian and transsexual people. According to the promoters of this campaign gender ideology (or gender theory) is the prerequisite for action that lesbian, gay, bisexual and transsexual people in particular (organized by the gay mafia which penetrate the social, educational, economic and political fabric of society of a country) are pursuing to impose: i) the denial of differences (even biological ones) between men and women; ii) the destruction of gender; iii) therefore, the destruction of the natural family; iv) the promotion of a homosexual lifestyle; v) the reverse discrimination of heterosexuals.

According to the narrative of these fundamentalist groups, the world of gay associationism (with which they mean all gay, lesbian and transsexual people) promote gender theory with the aim of transforming children into little neutral automatons, confused by their identity, in order to seduce them, subjugate them and incite them into promiscuity. To do this, they maintain that everyone can choose the gender to which they belong according to their tastes and whims. Gays, lesbians and transsexuals intend to abolish the biological differences between males and females and aim to overturn the natural family in favour of all sexual, social and educational aberrations. Gender has therefore wormed its way into schools, under the guise of sexual education projects, but which represents in fact the outcome of an illicit development and use of reproductive technology (such as surrogacy, incorrectly defined as a womb for rent). This means legitimizing and accepting paedophilia and opens the doors to baby factories. To properly understand the intentions of this campaign, however, it is necessary to understand the nature of fundamentalist thinking. 
The ghost of gender theory

To answer the question if gender theory exists the response is: no. Gender theory is the clearly distorted way in which this fundamentalist and reactionary campaign refers to gender studies, proposing an incorrect and false vision. The Italian term teoria del gender actually represents an altered simplification and a caricature-like translation of the English term gender theory, in which theory does not mean una teoria but rather the combination of theoretical studies. Scientific research, and common sense, allow us to think about the consequences of a renunciation of the extremely important notions of gender studies, which have a direct impact on life and growth, particularly in adolescents and young adults. Living and growing in an intolerant environment, that proposes frameworks that are too rigid, is a risk factor for psychological distress, especially in young people who are beginning to discover that they may be homosexual, bisexual or transsexual (Mac an Ghaill, 1994; Mayer, 2009). The same risk factor has an influence in turn on the increasing number of homophobe bullying episodes. On the other hand, the types of thought and reasoning that underly attacks against gender studies - precisely because they are based on an intuitive tradition (that is, a reasoning framework that is pre-critical and pre-scientific) that through the centuries, for the majority of people has become common belief - does not struggle to convince even those who cannot be identified as fundamentalists, but who nevertheless react instinctively and in fear in order to defend certitudes that have never been questioned. These are people who, in general terms, define themselves as open-minded, but who in the emotional climate created by the fundamentalist campaign feel threatened in their identity by the supposed gender theory. It is no coincidence, then, that the campaign in Italy is focusing on that which we usually focus our protective attention on, that is, children. With the slogan, "let's protect our children" the aim is to reawaken ancestral needs of protection towards weaker and defenceless individuals who, obviously, would be the victims of an elusive homosexual conspiracy. The task of scientific thinking, in this case, is to elucidate via which mechanisms habits transform into norms and from these norms become normativity (how is it possible to pass from: "things have always been like this" to: "things cannot be any other way, because they are right like this"), in order to show how even unexpected differences can result as perfectly functioning and must be safeguarded in development and identity.

Today and tomorrow: the misadventures of the gender phantom

Afterall we must consider that the specialization of disciplines and the speed of new discoveries has rendered them to a large extent incomprehensible to the majority of the population, albeit educated, for which there has 
been no thought as to adequate tools for dissemination. When people need to explain a complex phenomenon, and they do not have the tools of scientific analysis at hand, and when they do not reason, the anti-intellectual conspiracy theory is salvific for many because it is very simple; it indicates a guilty party, it helps to orient people and to cope with stress, it helps to sedate our artfully solicited atavistic fears, to reiterate our own closure towards a threatened identity: and the huge adherence to anti-gender movements is proof of this. This is a profiling of the typical strategies used by reactionaries: make the minorities rights seem like threats.

Thus, the imaginary but useful monster of gender ideology is conceived, a matrix and prototype for any danger; it is well-lit, radically simple and at the same time obscure, undetermined and ubiquitous. It works simultaneously as an explicative key and comfortable label for all those that do not know and do not want to take notice of modernity: in which the Church no longer has the ability to impose its point of view - and few follow it regarding norms of sexual moral- because the free world has matured a different sensitivity towards its commands. It is in fact necessary to view this campaign -also- as a regressive reaction to the escalating inability of religious leaders - who are intellectual, theological and institutional - to confront all the unresolved loose ends within Christianity and European Catholicism. A first loose end is certainly the evaluation of sexuality and the value attributed to this in terms of unexpected traditional norms, such as homosexuality, with the radical changes that this involves both in society and institutions. A second issue is the new affirmative force of women's rights and sexual minority groups, which are trying to give value to sentimental, relationship and identity pluralism, demonstrating the inability of the Church of maintaining its moral role, unless it changes with regard to these issues.

The conspiracy theory is self-generating. It is sufficient to explore reactionary Catholic sites to comprehend the directions it takes: if we faithful believers of the One Truth cannot make ourselves understood it is because the current institutions are corrupt, and this is because democratic systems do not have the force to defend the truth, ethics, and order from the attacks of malign forces. Lacking any rational discussion, the paranoid drift soon becomes a faith that is blind, irrational, subjectivist and authoritarian: the believer, exhausted and fearful, confides in the power-of the right- regressively soliciting him or her to defend it from anguish.

Civil society-except for a few early points of view ${ }^{1}$-arrived guiltily late, at first ignorant and then amazed by the demonstrated strength of the pro-

\footnotetext{
${ }^{1}$ Just two examples: the stance of the Italian Association of Psychologists in 2015 (and that of the Order of Psychologists of the Marche, Lazio and Puglia) and the article by Chiara Lalli, Tutti pazzi per il gender, In Internazionale.it, is dated 31 $1^{\text {st }}$ of March 2015.
} 
pagandist aberration. Thus, the world of secular associationism- and the more communicative part of the church- was subject to many months of an offensive, without clamping down on the paranoia that dominated on social media, much like in many parishes in all of Italy.

Nevertheless, right when the media campaign was becoming more and more violent and uncontrollable, the Church was forced to realise that it was setting off on an embarrassing and unsuccessful road, so much so that they had to distance themselves ${ }^{2}$ from it. In this way, the fundamentalist campaign began to die down, and incidentally did not impede the approval of a law on civil unions, against which it was obviously finalised. Surely, we must not deceive ourselves that this will not reappear with a renewed virulence and more astute propaganda strategies: perhaps intersecting other issues that upset collective sensitivity (such as immigration) and establishing alliances with other reactionary groups. In any case, its damage shall be felt for a long time: terrorized parents, divided communities, educators and professors who live in fear of condemnation from parents; topics that have again become taboo and halted educational programmes. The phantom of gender is at this point living among us, ready to receive new life, when needed.

\section{REFERENCES}

Adler, P.A., Kless, S.J., \& Adler, P. (1992). Socialization to Gender Roles: Popularity among Elementary School Boys and Girls. Sociology of Education, 65, 3, pp. 169-187.

Alesina, A.F., Giuliano, P., \& Nunn, N. (2011). On the Origins of Gender Roles: Women and the Plough. Working Paper n. 17098. National Bureau of Economic Research. Cambridge, MA.

Anthony, D.W. (2007). The Horse, the Wheel, and Language: How Bronze-Age Riders from the Eurasian Steppes Shaped the Modern World. Princeton University Press, Princeton.

Associazione Italiana di Psicologia (2015). Position statement sulla diffusione degli Studi di

Genere, 12/03/2015. Available from: http://www.aipass.org/files/AIP_position_ statement_diffusione_studi_di_genere_12_marzo_2015\%281\%29.pdf

Beal, C. (1994). Boys and Girls. The Development of Gender Roles. McGraw-Hill, New York. Belgiojoso, C. (1848). Della presente condizione delle donne e del loro avvenire. In: S. Bertone (a cura di), Il 1848 a Milano e a Venezia, con uno scritto sulla condizione delle donne, Feltrinelli, Milano 1977, pp. 169-174.

Bird, R. (1999). Cooperation and conflict: the behavioral ecology of the sexual division of labor. Evolutionary Anthropology 8, 2, pp. 65-75.

Brustad, R.J. (1996). Attraction to Physical Activity in Urban Schoolchildren: Parental

\footnotetext{
${ }^{2}$ The decision of the Episcopal Conference of Italy to not bless Family Day in June 2015; the article of Giaccardi C. (2015), Non solo ideologia: riappropriamoci del gender, published in the magazine Avvenire on the $31^{\text {st }}$ of July; the very firm denunciation of the pedagogist and editorialist Pellai of Avvenire magazine in 2015, the publications of Aristide Fumagalli (2015) and Lucia Vantini (2015) the stance taken by the Diocese of Padova who ushered in other more appropriate and placid ideas...
} 
Socialization and Gender Influences. Research Quarterly for Exercise and Sport, 67, 3, pp. 316-323.

Butler, J. (1990). Gender Trouble. Feminism and the Subversion of Identity. Routledge, Chapman \& Hall, NY.

Chaplin, T.M., Cole, P.M., \& Zahn-Waxler, C. (2005). Parental Socialization of Emotion Expression: Gender Differences and Relations to Child Adjustment. Emotion, 5 (1), pp. $80-88$.

Clearfield, M.W. \& Nelson, N.M. (2006). Sex Differences in Mothers' Speech and Play Behavior with 6-, 9-, and 14-Month-Old Infants. Sex Roles, 54, 1-2, pp 127-137.

Connell, R. (2009 II ed.), Questioni di genere, Il Mulino, Bologna 2011, p. 112.

De Gouges, O. (1793). Dichiarazione dei diritti della donna e della cittadina. Il Bimestrale, 1989, anno I, n.1, pp. 17-18.

Dill, K.E. \& Thill, K.P. (2007). Video Game Characters and the Socialization of Gender Roles: Young People's Perceptions Mirror Sexist Media Depictions. Sex Roles, 57, 11, pp. 851-864.

Durham, M.G. (1999). Girls, Media, and the Negotiation of Sexuality: A Study of Race, Class, and Gender in Adolescent Peer Groups. Journalism \& Mass Communication Quarterly, 76, 2, pp. 193-216.

Eccles, J.S., Jacobs, J.E, \& Harold, R.D. (1990). Gender Role Stereotypes, Expectancy Effects, and Parents' Socialization of Gender Differences. Journal of Social Issues, 46, 2, pp. 183-201.

Edgerton, R.B. (2000). Warrior Women: The Amazons of Dahomey and the Nature of War. Westview Press, Boulder.

Endicott, K. (1999). Gender relations in hunter-gatherer societies. In: Lee, R.B., Daly, R. (eds), The Cambridge Encyclopedia of Hunters and Gatherers, Cambridge University Press, Cambridge, pp. 411-418.

Ferrari, F. (2016). Pensare il genere e parlare di genere. In: Genius, 3, 2, 178-192.

Fivush, R., Brotman, M.A., Buckner, J.P., \& Goodman, S.H. (2000). Gender Differences in Parent- Child Emotion Narratives. Sex Roles, 42, 3-4, pp 233-253.

Fumagalli A. (2015). La questione gender: una sfida antropologica, Queriniana, Brescia Garside, R.B. \& Klimes-Dougan, B. (2002). Socialization of Discrete Negative Emotions: Gender Differences and Links with Psychological Distress. Sex Roles, 47, 3-4, pp. 115128.

Giaccardi, C. (2015). Non solo ideologia: riappropriamoci del gender. Avvenire, 31 luglio. Available from: https://www.avvenire.it/famiglia-e-vita/pagine/gender-non-soloideologia-riappropriamoci-del-genere-

Hardin, M. \& Greer, J. D. (2009). The Influence of Gender-role Socialization, Media Use and Sports Participation on Perceptions of Gender-Appropriate Sports. Journal of Sport Behavior, 32, 2, pp. 207-226.

Henningsen, G. (1990). L'avvocato delle streghe. Stregoneria basca e Inquisizione spagnola. Garzanti, Milano.

Holtzman, L. \& Sharpe, L. (2015). Media Messages: What Film, Television, and Popular Music Teach Us About Race, Class, Gender, and Sexual Orientation. Routledge, New York.

Karraker, K.H., Vogel, D.A., \& Lake, M.A. (1995). Parents' gender-stereotyped perceptions of Newborns: The Eye of the Beholder revisited. Sex Roles, 33, 9-10, pp. 687-701.

King, M.L. (1991). Le donne nel Rinascimento. Laterza, Roma-Bari.

Lalli, C. (2015). Tutti pazzi per il gender. Internazionale, 31 marzo.

Available from: https://www.internazionale.it/opinione/chiara-lalli/2015/03/31/teoriagender-diritti

Leaper, C. \& Friedman, C.K. (2007). The Socialization of Gender, in J.E. Grusec, \& P.D. 
Hastings (eds), Handbook of Socialization: Theory and Research, The Guilford Press, New York, pp. 561-587.

Lloyd, B., \& Duveen, G. (1990). A semiotic analysis of the development of social representation of gender. In: Duveen, G., \& Lloyd, B. (eds) Social Representation and the Development of Knowledge. Cambridge University Press, New York.

Mac an Ghaill, M. (1994). The Making of Men: Masculinities, sexualities and schooling. Open University Press, Maidenhead.

Mayer, E.J. (2009). Gender, Bullying and Harassment. Strategies to End Sexism and Homophobia in Schools. Columbia University Press, New York.

Pellai, A. (2015). A proposito dell'ideologia gender. Avvenire, 16 marzo.

Saraceno, C. (1996). Genere. La costruzione sociale del femminile e del maschile. Il Mulino, Bologna.

Serravalle Porzio, E. (a cura di) (2001). Saperi e libertà: maschile e femminile nei libri, nella scuola e nella vita. Associazione Italiana Editori, Milano.

Vantini L. (2015) Genere, Messaggero, Padova

Weerman, F.M. (2012). Peers and delinquency among girls and boys: Are sex differences in delinquency explained by peer factors? European Journal of Criminology, 9, 3, pp. 228244.

Wollstonecraft, M. (1792). A vindication of the Rights of Woman. Boston.

Conflict of interest: the authors declare no potential conflict of interests.

Ethics approval and consent to participate: the manuscript does not contain any elements that would allow the recognition of the patient.

Received for publication: 5 March 2020.

Accepted for publication: 5 May 2020.

${ }^{\mathrm{C}}$ Copyright: the Author(s), 2020

Licensee PAGEPress, Italy

Ricerca Psicoanalitica 2020; XXXI:267

doi:10.4081/rp.2020.267

This article is distributed under the terms of the Creative Commons Attribution

Noncommercial License (by-nc 4.0) which permits any noncommercial use, distribution,

and reproduction in any medium, provided the original author(s) and source are credited. 